Revista de Derecho

de la Pontificia Universidad Católica de Valparaíso

LV (Valparaíso, Chile, 2do semestre de 2020)

[pp. 289-301]

\title{
EL PRINCIPIO DE INTERVENCIÓN MÍNIMA EN EL Arbitraje COMERCIAL INTERNACIONAL: A PROPÓSITO \\ DE UNA CUESTIONABLE SENTENCIA DICTADA POR LA Corte Suprema de Chile
}

[The Minimum Intervention Principle in International Commercial Arbitration: The Case of a Questionable Ruling by the Chilean Supreme Court]

\section{María Fernanda Vásquez Palma* Universidad de Talca}

RECiBido el 07 de diciembre de 2020 y AcEPTADO el 01 de marzo de 2021

\section{LOS HECHOS}

El fallo que analizaremos en estas líneas fue dictado por la Excelentísima Corte Suprema (CS) en la causa rol No $19.568-2020$, con fecha 14 de septiembre de 2020. Resumidamente, versa sobre un juicio arbitral de carácter internacional seguido en el centro de arbitraje y mediación de la Cámara de Comercio de Santiago (CCS), a partir de conflictos que se suscitaron por una compraventa de acciones entre las partes. En contra del laudo arbitral dictado en dicho juicio se presentó un recurso de apelación ante la Ilustre Corte de Apelaciones de Santiago (CA de Santiago), la que lo declaró inadmisible por considerarlo contrario a la Ley $\mathrm{N}^{\circ} 19.971$, sobre arbitraje comercial internacional. El recurrente presentó un recurso de reposición en contra de esta decisión y al ser rechazado nuevamente por la CA de Santiago, recurrió de queja ante la CS. Este tribunal si bien no acogió este recurso, de oficio anuló las resoluciones pronunciadas por la CA de Santiago en base al principio de buena fe procesal y de acceso a la justicia.

Para una mejor intelección de este caso, revisaremos ambas decisiones, esto es, la pronunciada por la CA de Santiago y por la CS, para someterlas a un necesario análisis jurídico.

* Profesora Titular de Derecho privado en la Universidad de Talca. Doctora en Derecho por la Universidad Complutense de Madrid. Correo electrónico: mfvasquez@utalca.cl. 
En lo medular, la sentencia pronunciada por la CA de Santiago (rol $\left.\mathrm{N}^{\circ} 12017-2019\right)$ resolvió, con fecha 16 de enero de dos mil veinte, que el recurso de apelación interpuesto en contra del laudo de arbitraje comercial internacional tramitado ante la CCS no procedía por las siguientes razones: 1. que según el artículo 19 de la Ley $\mathrm{N}^{\circ} 19.971$, sobre arbitraje comercial internacional, las partes tendrán libertad para convenir el procedimiento a que se haya de ajustar el tribunal arbitral en sus actuaciones, pero aquella autonomía se ejercerá con sujeción a las disposiciones de esta misma ley; 2. que según el artículo 34 de la ley en comento, contra un laudo arbitral sólo podrá recurrirse ante un tribunal mediante una petición de nulidad, siendo este el único medio de impugnación que esta ley dispone; 3. que sin perjuicio de lo acordado por las partes en el numeral 17 de las bases del arbitraje, que versa sobre los recursos, el que señala que contra la sentencia definitiva serán procedentes los recursos de apelación y casación en la forma, por encontrarse esta disposición en expresa contravención a lo establecido en la Ley sobre arbitraje comercial internacional, el arbitrio que se eleva no puede ser admitido a tramitación. En base a lo anterior, y lo dispuesto en los artículos 201 y 213 del Código de Procedimiento Civil, se declara inadmisible la apelación interpuesta en contra del laudo arbitral, con fecha 20 de agosto de 2019, en contra de la sentencia definitiva de 2 del mismo mes y año'.

En contra de esta decisión se presentó un recurso de reposición, el que igualmente fue rechazado con fecha 12 de febrero de 2020. En contra de esta última resolución se presentó un recurso de queja ante el tribunal superior.

La CS sometió a trámite el recurso de queja. Evacuando el informe de rigor, los jueces recurridos expusieron que, si bien las partes establecieron en las bases del arbitraje que en contra de la sentencia definitiva serían procedentes los recursos de apelación y casación en la forma, dicha cláusula contravenía lo dispuesto en los artículos 19 y 34 de la Ley $\mathrm{N}^{\circ} 19.971$ sobre arbitraje comercial internacional. Se añade que el recurrente, al momento de suscribir el contrato que dio origen al presente juicio fijó domicilio en México, configurándose así el primero de los requisitos para entender que el arbitraje en cuestión tenía el carácter de internacional, lo que hace aplicable a su respecto la citada ley. Se concluye indicando que no han incurrido en falta o abuso grave, sino que se han limitado a interpretar la normativa aplicable al caso.

${ }^{1}$ Sentencia pronunciada por la Primera Sala de la Ilma. Corte de Apelaciones de Santiago, presidida por la Ministra señora Dobra Lusic Nadal y conformada por el Ministro señor Rafael Andrade Díaz y el Abogado Integrante señor Rodrigo Asenjo Zegers. 
Nuestro máximo tribunal, para resolver la queja, sostuvo lo siguiente:

1. Que ante la CCS el abogado Jiménez Parada presentó solicitud de inicio de arbitraje comercial internacional por sus representadas Sudamérica SpA y CCF Sudamérica SpA, lo que dio origen al proceso №3048-2017, que culminó con la sentencia definitiva. Dicha decisión fue impugnada por la parte demandante mediante recurso de apelación, arbitrio que el tribunal a quo tuvo por interpuesto, para luego concederlo y elevar los antecedentes al tribunal de alzada.

2. Que la Sala Tramitadora de la CA de Santiago declaró inadmisible el recurso de apelación, argumentando que tratándose de un arbitraje comercial internacional resultaban aplicables las disposiciones de la Ley $\mathrm{N}^{\circ} 19.971$, destacando que su artículo 34 dispone que contra un laudo arbitral sólo podrá recurrirse ante un tribunal mediante una petición de nulidad, siendo este el único medio de impugnación que dicha ley dispone, de modo que, sin perjuicio de lo acordado por las partes en las bases del arbitraje, la apelación no puede ser admitida a tramitación.

3. Dicho pronunciamiento fue objeto de un recurso de reposición y mediante resolución de fecha 12 de febrero de 2020 la CA de Santiago lo desestimó bajo el mismo razonamiento.

4. Que el artículo 545 del Código Orgánico de Tribunales concede el recurso de queja en contra de resoluciones de carácter jurisdiccional dictadas con falta o abuso, con la sola limitación de que dichas resoluciones pongan término al juicio o hagan imposible su prosecución.

5. Que el mérito de los antecedentes tenidos a la vista y aquellos agregados al recurso no permiten concluir que los ministros recurridos, al decidir como lo hicieron, hayan incurrido en alguna de las conductas que la ley reprueba y que sería necesario reprimir y enmendar mediante el ejercicio de las atribuciones disciplinarias de esta Corte. Lo cuestionado, en definitiva, es la interpretación y aplicación de un precepto legal efectuada por ellos sobre la base de un razonamiento que fue explicado suficientemente en la resolución que censura la quejosa. De este modo, la ECS rechaza el recurso de queja deducido por el abogado José Ignacio Jiménez Parada.

Sin perjuicio de lo anterior y a fin de justificar la decisión que más adelante se adoptará, este Tribunal estima pertinente tener en consideración las siguientes cuestiones:

$1^{\circ}$ Que resulta necesario recordar que el arbitraje voluntario no nace de la ley, son las partes las que, de común acuerdo, a través de un convenio arbitral proceden a encomendar la resolución del asunto a un tribunal arbitral. 
$2^{\circ}$. En nuestro derecho el convenio arbitral puede provenir de dos actos: del contrato de compromiso o de la cláusula compromisoria. La cláusula compromisoria es un acuerdo de voluntades mediante la cual las partes acuerdan someter un asunto litigioso futuro y eventual a la resolución de un árbitro. En otros términos, la cláusula compromisoria es un contrato por el cual las partes sustraen determinados asuntos litigiosos presentes $o$ futuros, al conocimiento de las jurisdicciones ordinarias (o especiales), y las someten a juicio arbitral, obligándose a nombrar al árbitro o árbitros en un acto posterior. El compromiso arbitral se diferencia de la cláusula compromisoria porque esta expresa la intención general de las partes de someter sus asuntos litigiosos al conocimiento de los árbitros que no han sido personificados aún. Aunque este tipo de pacto no se encuentra contemplado en la ley, su validez actualmente no se pone en duda.

$3^{\circ}$. En el arbitraje en general el consentimiento prestado por las partes en orden a someterse a este tipo de procedimiento resulta ser esencial. Que del análisis de autos se advierte que las partes, al suscribir el contrato de compraventa de acciones que dio origen al presente juicio, en su cláusula decimotercera, determinó que "El presente Contrato de Compraventa se regirá e interpretará conforme a las leyes de la República de Chile". En la misma cláusula, numeral 12, establecieron que "Todas las disputas que surjan de este contrato o que guarden relación con el presente Contrato o la ejecución de los actos aquí pactados o respecto de cualquier motivo relacionado con el presente Contrato, se resolverá mediante arbitraje, de acuerdo con el Reglamento de Arbitraje Comercial Internacional del Centro de Arbitraje y Mediación de la CCS, vigente al momento de su inicio".

$4^{\circ}$. Que los mismos contratantes al constituir las bases del compromiso, en cuanto a las normas aplicables a la conducción del procedimiento, acordaron que "El arbitraje se regirá por el Reglamento de Arbitraje Internacional del Centro de Arbitraje y Mediación de Santiago, en adelante el Reglamento, y los Estatutos de la CCS en actual vigencia, con las modificaciones que constan en la presente acta. En lo no previsto se estará a la voluntad de las partes, en su defecto a la del Tribunal Arbitral. Supletoriamente se aplicarán las normas del Código de Procedimiento Civil y Código Orgánico de Tribunales". También señalaron que "Respecto a la sentencia definitiva se estará a lo establecido en la cláusula arbitral, esto es, serán procedentes los recursos de apelación y casación en la forma".

$5^{\circ}$. Que, siendo la cláusula compromisoria independientemente de su naturaleza institucional, doméstica o internacional, de carácter consensual, el sentenciador debe tener en consideración la intención de las partes al 
contratar y su comportamiento posterior. En este sentido es preciso traer a colación el principio de la buena fe procesal, recogido por la doctrina y jurisprudencia, entendida como una cláusula que contribuye a que el juez dicte una sentencia justa, en tanto las partes deben ayudar al tribunal a conseguir, en el lenguaje del proceso civil inglés, "el objetivo primordial del juicio". Este fin primordial no puede ser otro que un veredicto justo.

$6^{\circ}$. Dado que los litigantes no pueden ir en contra de sus propias actuaciones, no es posible soslayar que al momento de suscribir la cláusula compromisoria las partes determinaron que cualquier conflicto sería sometido a arbitraje, el que se regiría por el Reglamento de Arbitraje Internacional del Centro de Arbitraje y Mediación de la CCS, sin aludir a la Ley $\mathrm{N}^{\circ} 19.971$. Destacan, además, que en las partes libre y voluntariamente, establecieron que "respecto a la sentencia definitiva se estará a lo establecido en la cláusula arbitral, esto es, serán procedentes los recursos de apelación y casación en la forma”.

$7^{\circ}$. Que, en estrados, los litigantes dieron cuenta que posteriormente, con ocasión de otros conflictos que se suscitaron a raíz del mismo contrato de compraventa de acciones, modificaron los términos de sus Bases del Procedimiento, eliminando la procedencia del recurso de apelación. Esta circunstancia revela que después de un mayor análisis se estimó necesario adecuarlas a la Ley $\mathrm{N}^{\circ} 19.971$ pero, para los efectos de este juicio, en su inicio y tramitación consideraron como mecanismo válido de revisión el recurso de apelación. En otras palabras, no se había contemplado como alternativa recursiva válida el recurso de nulidad especial contemplado en la citada ley. Estiman que, entenderlo de otro modo, atentaría contra el principio de la buena fe procesal, que recoge como uno de sus elementos él no ir en contra de las propias actuaciones que los litigantes han desplegado durante el juicio.

$8^{\circ}$. Que, al declararse inadmisible el recurso de apelación deducido en autos en contra de la sentencia definitiva dictada por el tribunal arbitral, se privó a uno de los litigantes del mecanismo de revisión que los contratantes expresamente habían estipulado. En este punto, no es posible soslayar que nuestro sistema procesal consagra la existencia de diversos principios que pretenden asegurar la racionalidad y justicia del procedimiento. Entre ellos, el derecho al recurso, que se traduce en el de impugnar las resoluciones judiciales para proveer su revisión, mismo que integra el amplio espectro del derecho al debido proceso.

Agrega que, ligado a lo dicho, deben considerarse los derechos de acceso a la justicia y de tutela judicial efectiva, lo que conduce a que en el proceso de interpretación de normas se prefiera aquella que permite el acceso a la jurisdicción, a obtener una sentencia motivada y, en su 
caso, el cumplimiento de lo resuelto. En la perspectiva recién indicada, surge con nitidez, entonces, la necesidad de interpretar restrictivamente las normas que pudieran dar pábulo a limitar o restringir tales derechos o garantías.

En consecuencia, la ECS resuelve de oficio invalidar las resoluciones de 16 e enero y 12 de febrero del año en curso, del expediente Rol $N^{\circ} 12017$ 2019, tramitado ante la CA de Santiago, en cuanto declarar inadmisible el recurso de apelación y desestimar el recurso de reposición intentado en contra de dicha declaración de inadmisibilidad, respectivamente, y declarar en su lugar que la apelación deducida en contra de la sentencia dictada con fecha 2 de agosto de 2019 es admisible, para cuyo efecto la Corte de Apelaciones proveerá la presentación del recurrente dando curso progresivo a los autos.

\section{ANÁlisis Jurídico de eSte fallo}

La sentencia dictada por la ECS es preocupante, pues con ella se vulneran algunos principios fundamentales del arbitraje comercial internacional. En lo medular, esta sentencia, comente dos yerros: a. declarar procedente el recurso de queja en contra de la sentencia pronunciada por los ministros de la corte de apelaciones; $\mathrm{y} b$ b. anular de oficio las resoluciones dictadas por la CA de Santiago a las que nos hemos referido. Lo anterior se explica a priori sobre la base de un inadecuado entendimiento de la institución del arbitraje internacional, lo que se colige de los propios fundamentos señalados en la sentencia analizada. En particular: a. se alude al arbitraje voluntario y forzoso en relación con arbitraje internacional; b. se refiere a una distinción entre cláusula compromisoria y compromiso en un arbitraje comercial internacional; c. se sostiene que las partes, pese a someterse a un arbitraje internacional y a Santiago como sede arbitral, no habrían elegido a la Ley $\mathrm{N}^{\circ} 19.971$ como aplicable, sino el reglamento de arbitraje comercial internacional de la CCS, la voluntad de las partes, y las normas procesales de derecho interno; $\mathrm{y} \mathrm{d}$. finalmente, pregona que el acuerdo de las partes prevalece sobre lo dispuesto en la Ley $\mathrm{N}^{\circ} 19.971$, y sobre esta base procede de oficio a invalidar la resolución que declara inadmisible el recurso de apelación y la que desestimó el recurso de reposición interpuesto en contra de esta última.

Estas afirmaciones son erróneas, según pasamos a explicar a continuación.

\section{Ambito de aplicación del principio de intervención minima en el arbi-} traje comercial internacional

Los tribunales arbitrales son de índole privada, de manera que la compe- 
tencia de estos tribunales siempre debe emanar de las partes que disponen de dicha facultad. El instituto arbitral sólo es factible en aquellas materias arbitrables (patrimoniales o disponibles), en la medida que, si las partes de un conflicto pueden solucionarlo por sí mismas, también pueden confiar tal resolución a un tercero. Se trata de un derecho inherente a la calidad de sujeto y ciudadano, de forma que al legislador sólo le corresponde reconocer tal derecho y velar por ciertas garantías procesales fundamentales, como el debido proceso y el acceso a la justicia.

En Chile el arbitraje si bien ha funcionado desde hace más de un siglo en derecho interno, sólo en el año 2004 por medio de la dictación de la Ley $\mathrm{N}^{\circ} 19.971$ sobre arbitraje comercial internacional, se reconocieron los elementos esenciales de aquél, de manera que en la actualidad coexisten dos arbitrajes: uno arcaico y otro respetuoso de la institucionalidad.

A partir del arbitraje comercial internacional se consagra el principio de intervención mínima (arts. 5 y 6 de la Ley $\mathrm{N}^{\circ} 19.971$ ), que impide que los tribunales estatales de la sede intervengan más allá de lo necesario. Es decir, sólo se les requiere para brindar apoyo ${ }^{2}$ y controlar el laudo ${ }^{3}$. Esto implica que los tribunales estatales no pueden intervenir más allá de lo estrictamente regulado ${ }^{4}$. Traspasar esta frontera provoca una vulneración de la autonomía de la institución arbitral, de la voluntad de las partes y de los efectos del contrato arbitral's.

${ }^{2}$ Lo consagrado en el artículo $5^{\circ}$ es un principio básico del instituto arbitral, en cuanto busca una actuación limitada de los tribunales ordinarios de justicia en el procedimiento arbitral. De este modo, y caso en contrario, cabe mencionar las actuaciones en las cuales sí pueden intervenir estos tribunales, situaciones contempladas en el artículo $6^{\circ}$ de la Ley $\mathrm{N}^{\circ} 19.971$, las que corresponden a: la designación de árbitro a falta de acuerdo de las partes (artículo 11 números 3 y 4); decidir sobre la procedencia de una recusación cuando el árbitro ya la ha rechazado (artículo 13 número 3); pronunciarse sobre la excepción de incompetencia cuando el árbitro ya la ha rechazado (artículo 16 número 3); en caso de que exista desacuerdo sobre si se dan los motivos para considerar que el árbitro ha cesado en sus funciones, deberá decidir si ha cesado el mandato (artículo 14) y pronunciarse sobre la petición de nulidad de la sentencia arbitral (artículo 34 número 2). Las funciones a las cuales se refieren los artículos 11, numerales 3 y 4; 13, numeral 3; 14 y 16, numeral 3 de la Ley $N^{\circ} 19.971$, serán ejercidas por el Presidente de la Corte de Apelaciones del lugar donde debe seguirse o se sigue el arbitraje, y la del artículo 34, numeral 2, será desempeñada por la respectiva Corte de Apelaciones.

${ }^{3}$ De conformidad al art. 34 de la Ley N¹9.971.

${ }^{4}$ Vid. Goswami, Luis, Interim Reliefs: The Role of the Courts, Internacional Arbitration and Nacional Courts: The Never Ending Store, en ICCA International Arbitration Conference (La Haya, Kluwer Law International, 2001) pp. 111 y ss.

${ }^{5}$ Vid. VÁsquez Palma, María Fernanda, Tratado de arbitraje en Chile, Arbitraje 
Lamentablemente esta tradición anómala en cuanto revisar el fondo de lo debatido en el juicio arbitral o corregir las sentencias arbitrales y sancionar a los árbitros por medio de la queja, viene del inadecuado entendimiento que se ha prodigado desde el siglo XXVIII respecto del arbitraje interno. La explicación es histórica, como sabemos en un inicio el arbitraje requería de una cláusula penal para brindar cierta seguridad al cumplimiento del fallo. Esto mutó y se confirió fuerza obligatoria al laudo, pasando a ser regulado en códigos procesales, olvidando su aspecto civil esencial que no es otro que la piedra angular de todo arbitraje: el contrato arbitral. Llegada la conquista española el arbitraje se incorporó en la normativa chilena como vía de solución de conflictos, por normas constitucionales que luego se trasladaron a códigos procesales ${ }^{6}$. En consideración a ello se ha prodigado una naturaleza jurisdiccional al arbitraje, dejándolo en una zona nebulosa que no resiste análisis en el día de hoy; sin embargo, tal situación no ha sido remediada ni por el legislador, ni por la jurisprudencia por vía interpretativa.

Al contrario de ello, la situación en materia internacional ha sido inmejorable, toda vez que los tribunales estatales que han ejercido el rol de juez de apoyo y control, esto es, las cortes de apelaciones y presidentes de aquellas han comprendido perfectamente las diferencias que habitan entre estos arbitrajes, aplicando correctamente la Ley $\mathrm{N}^{\circ} 19.971$. Así, por ejemplo, todos los recursos de queja interpuestos en sede de arbitrajes comerciales internacionales han sido sistemáticamente rechazados por la CA de Santiago 7 .

La ECS, al no ser un tribunal al que el legislador le haya dotado de competencia en esta materia especialmente, no está habituado a resolver estos casos, y quizá ello explica el por qué ha terminado confundiendo ambos estadios, con el consiguiente error anunciado, pues mezcla el arbitraje interno (y sus añejas nociones que aún no han sido reparadas por el legislador) con el arbitraje comercial internacional reconocido a partir de la Ley $\mathrm{N}^{\circ} 19.971$, que escasa vinculación tienen en Chile por falta de voluntad legislativa.

Sin ánimo de reparar en las numerosas distinciones que habitan entre ambos (la mayoría injustificadas, pues la institución es una) ${ }^{8}$, se precisa

interno e internacional ( $1^{\text {a }}$ edición, Santiago, Thomson Reuters, 2018) p. 150 y ss.

${ }^{6}$ Ibid., p. 101 y ss.

${ }^{7}$ A modo de ejemplo, la CA de Santiago ha rechazado los recursos de queja deducidos en causa rol No2363-2010, con fecha 23 de julio de 2010, y en el caso “D’Arcy Masius Benton \& Bowles Inc. Chile Ltda. V. Carlos Eugenio Jorquiera”, rol No 88-2006, con fecha 03 de mayo de 2006.

${ }^{8}$ Cuestión que ya ha sido analizada en nuestra doctrina. Vid. VÁsqueZ, cit. (n. 5). 
subrayar que el arbitraje comercial internacional presenta una clara delimitación en su ámbito de aplicación material (art. $1^{\circ}$ ), una definición consistente del contrato o acuerdo arbitral, sus modalidades (art. $7^{\circ}$ ) y efectos (arts. 8 y 16). Se consagran en la ley del ramo los principios que en la actualidad rigen a los arbitrajes modernos (internos e internacionales), como son: a. el principio de autonomía de arbitraje, en la medida que sólo se reconoce como tal el arbitraje que se inicia por medio de un acuerdo arbitral (no existen los arbitrajes forzosos) y las partes tienen amplias facultades para estipular el procedimiento y normativa aplicable; b. el principio de intervención mínima de los tribunales estatales (art. 5 y 6), en la medida que se entiende que el arbitraje requiere de los tribunales estatales de la sede elegida por las partes, en relación con apoyo en ciertas materias de procedimiento y en el control del laudo; c. el principio de separación o autonomía del contrato arbitral, que implica que si se discute la nulidad del contrato en que se inserta el acuerdo arbitral, éste último no se verá contaminado con dicha alegación; d. de la mano del anterior, encontramos el principio "Kompetenz-Kompetez", que implica que el tribunal arbitral es competente para pronunciarse sobre su propia competencia, pues de lo contrario sería una institución muy feble, en la que sólo bastaría poner en duda la competencia del árbitro para negar los efectos del contrato arbitral, perdiendo su ineficacia.

En este entramado no podemos dejar de mencionar que el arbitraje descansa en la libertad de las partes y en su autonomía de la voluntad, los tribunales arbitrales son autónomos respecto de la justicia estatal, en tanto jueces privados cuya competencia emana de las partes que son capaces de concederla (disponibilidad y arbitrabilidad del asunto sometido), y nunca de la ley, pues esta no tiene facultad alguna para obligar a las partes a someterse a un arbitraje, privándoles de su acceso a la justicia estatal, ni de inmiscuirse en el fondo de las decisiones que se adopten sobre esta materia?.

\section{Sobre el contrato arbitral y sus efectos en el arbitraje comercial inter- nacional \\ De la misma manera que en el arbitraje moderno no es posible hablar de arbitraje forzoso o voluntario, tampoco es apropiada la añeja distinción de cláusula compromisoria y compromiso a la que se alude en la sentencia pronunciada por la ECS, citando textos publicados a mediados del siglo}

${ }^{9}$ Sobre la forma y caso en que un tribunal local puede intervenir en relación con un arbitraje internacional. Vid. MAITRA, Neelanjan, Domestic Court Intervention in Internacional Arbitration-The English View, en Journal of International Arbitration 23 (2006) 3, pp. 239-248. 
pasado respecto del arbitraje interno ${ }^{10}$. En efecto, en la Ley $\mathrm{N}^{\circ} 19.971$ el acuerdo de arbitraje se presenta como un punto neurálgico y motor inicial y necesario para dar vida al arbitraje, en la normativa no se alude a las viejas nomenclaturas de compromiso y a la cláusula compromisoria, sino sólo al "convenio arbitral" ${ }^{11}$ Cuando la ley alude a "cláusula compromisoria" lo hace para referirse a la forma que puede adoptar este acuerdo, es decir, como un contrato independiente o como una cláusula incorporada a otro contrato. Este acuerdo debe referirse a una determinada relación jurídica pudiendo ser ésta contractual o no contractual ${ }^{12}$, distinción y referencia que no está hecha en el arbitraje doméstico.

El contrato arbitral es la piedra angular del instituto arbitral, como genuina manifestación de la autonomía de la voluntad y siempre dentro de los límites de su ejercicio, de manera tal que si no existe un acuerdo no puede haber un arbitraje válido. Constituye, por tanto, un elemento esencial por constituir su fuente por excelencia. Este acuerdo configura un contrato de carácter privado que tiene unos efectos de marcado carácter procesal, toda vez que su principal objeto es la creación de una competencia arbitral, renunciando de paso a la judicatura ordinaria o especial prevista en la ley y que, de no mediar tal acuerdo, le correspondería conocer de la materia en cuestión.

$\mathrm{El}$ acuerdo arbitral tiene anudados ciertos efectos. Desde la perspectiva sustantiva, como todo contrato, tiene el clásico efecto de ley para las partes (art. 1545 del Código Civil); y desde un enfoque negativo o procesal, esta consecuencia se traduce en la imposibilidad de los tribunales estatales de inmiscuirse en el arbitraje, más allá de lo planteado por el legislador en la normativa aplicable, esto es, el respeto del principio de intervención mínima.

De todas las afirmaciones realizadas por la ECS, la lectura realizada de la cláusula arbitral en cuestión es la que merece seguramente mayores

${ }^{10}$ Como ocurre en el clásico manual de Aylwin Azócar, Patricio, El Juicio Arbitral (1 ${ }^{a}$ edición, Santiago, Editorial Jurídica de Chile, 1948) p. 21. En detalle, vid. VÁsQueZ, cit. (n. 5).

${ }^{11}$ Definido en su art. 7 número 1 en el siguiente sentido: "Acuerdo de arbitraje es un acuerdo por el que las partes deciden someter a arbitraje todas las controversias o ciertas controversias que hayan surgido o puedan surgir entre ellas respecto de una determinada relación jurídica, contractual o no contractual. El acuerdo de arbitraje podrá adoptar la forma de una cláusula compromisoria incluida en un contrato o la forma de un acuerdo independiente".

${ }^{12}$ Se le da a esta expresión una interpretación amplia, de modo que abarque todos los asuntos comerciales no contractuales que ocurran en la práctica. Para notas de la Ley Modelo, vid. Organización de las Naciones Unidas, Anuario de la Comisión de las Naciones Unidas para el Derecho Mercantil Internacional XVI (1985), p. 120. 
reparos, pues a partir de aquella se pone en duda la aplicación de la Ley $\mathrm{N}^{\circ} 19.971$. Nótese que aquí no se discutió si el conflicto tenía o no carácter internacional (se partió de esta base), ni tampoco se debatió sobre la sede arbitral elegida por las partes (se entendió que la sede era Santiago y que las partes habían elegido atenerse a las normas del centro arbitral de la CCS), pero a pesar de ello, inusitadamente la ECS entendió que primaba lo señalado en el contrato y no lo dispuesto por la Ley $\mathrm{N}^{\circ} 19.971$.

Resulta evidente que la ley no requiere de una mención especial de las partes para regir el asunto si se dan los presupuestos para su aplicación, distinto es si estas pueden excluir la aplicación de uno o más preceptos, facultad que dependerá básicamente de si se trata de una norma de orden público o no.

En el presente juicio las partes acordaron resolver sus conflictos de acuerdo con las normas del arbitraje comercial internacional y eligieron como sede de este arbitraje la ciudad de Santiago de Chile (Art. 20 de la Ley $\mathrm{N}^{\circ} 19.971$ ). En otras palabras, optaron por un arbitraje comercial internacional en Chile y ello conllevaba innegablemente la aplicación de la Ley $\mathrm{N}^{\circ} 19.971\left(\operatorname{art} 1^{\circ}\right)$. Si bien esta normativa plantea un grueso campo de libertad a las partes en relación con el procedimiento, el principio de intervención mínima no está dentro de este manto de autonomía, pues de ser así, se desconfigura la esencia de este arbitraje (art. 19 de la Ley $\mathrm{N}^{\circ}$ 19.971).

En otras palabras, si las partes hubiesen querido establecer un recurso de apelación en un arbitraje internacional, este tendría que haber sido de idéntica naturaleza, es decir, una apelación ante un tribunal arbitral de segunda instancia. La casación no es procedente en ningún caso, por ello existe el recurso de nulidad. Siendo así, y dado que en la especie el único recurso o acción susceptible de interponer era el de nulidad, de conformidad a lo dispuesto en el art. 34 de la Ley $\mathrm{N}^{\circ} 19.971$, la CA de Santiago resolvió perfectamente, pues no procedía el recurso de apelación bajo ningún respecto.

De este modo, si la ECS quería aplicar la doctrina de los actos propios debió fallar en este sentido, justamente respetando la voluntad de las partes en orden a someterse a un arbitraje comercial internacional en Chile, pues es la ley de la sede (en este caso la $N^{\circ} 19.971$ ) la que debía aplicar a estos efectos.

\section{Correcta intelección de la cláusula arbitral suscrita en esta causa}

Sabiendo que no es posible soslayar el principio de intervención mínima establecido en los arts. 5 y 6 de la Ley 19.971, por tratarse de un principio indisponible y un efecto esencial del contrato arbitral, ¿cómo 
debemos entender lo estipulado por las partes, en cuanto a posibilitar un recurso de casación y apelación?

La cuestión es simple y ha sido ampliamente estudiada a partir de los acuerdos patológicos o defectuosos. Un contrato arbitral errado no necesariamente será ineficaz o nulo, si de su esencia podemos desprender la reunión de los elementos esenciales, como son: el consentimiento (y capacidad) de las partes, la arbitrabilidad del asunto sometido a arbitraje, y la escrituración, si era necesaria. Considerando la conservación del contrato que impera en materias comerciales internacionales, y que en arbitraje adopta el nombre de favor arbitraje, el acuerdo arbitral puede entenderse válido tachando la parte que se entiende defectuosa.

En tal contexto, debemos distinguir al convenio patológico, que es aquel que por defecto en la redacción, insuficiencia en el contenido, o errores en la determinación de sus elementos constitutivos, resulta ineficaz para establecer el proceso y no puede cumplir las cuatro funciones que le son esenciales, como son: producir efectos obligatorios entre las partes, apartar la intervención entre los tribunales estatales, conferir a los árbitros el poder para fallarse la controversia y permitir la puesta en marcha del proceso arbitral; de aquél que, siendo defectuoso, puede prosperar luego de realizar una labor interpretativa, debiendo considerar para ello que no todos los errores cometidos en el convenio presentan idénticas consecuencias.

En el presente juicio, el contrato arbitral era válido, y la parte en que hacía referencia a la posibilidad de interponer los recursos de apelación y casación en la forma contrariaba una norma de orden público de la ley aplicable a este arbitraje, de manera que sólo correspondía entender que aquella se tendría por no escrita, evitando todo lo que posteriormente sucedió. En este orden de ideas, lo que debió suceder es una interpretación adecuada del acuerdo arbitral, que -en base a su validez- entendiese que esa frase no podía ser aplicable bajo ningún respecto, por contrariar los arts. 5, 6 y 19 de la Ley $\mathrm{N}^{\circ} 19.971$. Esta era la verdadera intención de las partes y prueba de ello es que luego se modificaron otros acuerdos existentes en esta misma dirección.

\section{CONCLUSIÓN}

El fallo analizado ha contrariado las bases de la institución arbitral misma, si bien en este caso no es posible hacer más, esperamos que en lo sucesivo esta situación no se reitere. De ser así, nuestro país como posible sede de arbitraje se convierte en una ilusión, pues nadie querrá asumir el riesgo de que los tribunales estatales desdibujen los cimientos de la ley aplicable, poniendo en jaque el principio de intervención mínima. 
Desde una perspectiva más amplia, esta sentencia pone en evidencia la falta de preparación en esta materia de nuestra judicatura, lo que también se hace extensivo al mundo profesional. Desde luego la doctrina consultada y mencionada en el fallo nos evoca una gran preocupación ${ }^{13}$.

Resulta urgente enmendar esta ruta preparando mejor a los jueces y abogados, pero también lo es el reformar el arbitraje interno, a fin de que el instituto arbitral abandone los resabios anacrónicos del siglo XVIII y se sume a la modernización de la justicia arbitral de manera integral.

\section{BiBLIOGRAFÍA}

Aylwin AzóCAr, Patricio, El Juicio Arbitral (1ª edición, Santiago, Editorial Jurídica de Chile, 1948).

Biggs BRuna, Gonzalo, Solución de controversias sobre comercio e inversiones internacionales, en Revista CEPAL 80 (2003) p. 42.

Dougnac Rodríguez, Antonio, Antecedentes históricos sobre la regulación del arbitraje en Chile, en Estudios de arbitraje. Libro homenaje al profesor Patricio Aylwin Azócar (Santiago, Editorial Jurídica de Chile, 2007) pp. 56 y ss.

Goswami, Luis, Interim Reliefs: The Role of the Courts, Internacional Arbitration and Nacional Courts: The Never Ending Store, en ICCA International Arbitration Conference (La Haya, Kluwer Law International, 2001) pp. 111 y ss.

JEQUIER LEHUEDÉ, Eduardo, El arbitraje forzoso en Chile (Un examen de constitucionalidad en el ordenamiento jurídico chileno), en Revista de Estudios Constitucionales 9 (2011) 2, pp. 460-475.

Maitra, Neelanjan, Domestic Court Intervention in Internacional Arbitration-The English View, en Journal of International Arbitration 23 (2006) 3, pp. 239-248.

Organización de las Naciones Unidas, Anuario de la Comisión de las Naciones Unidas para el Derecho Mercantil InternacionaL XVI (1985).

Redfern, Alan - Hunter, Martin - Blackaby, Nigel, Teoría y práctica del arbitraje comercial internacional (4a edición, Navarra, Thomson Aranzadi, 2006).

Romero Seguel, Alejandro, Nociones generales sobre la justicia arbitral, en Revista Chilena de Derecho 26 (1999) 2, pp. 405-430.

Romero SEGUel, Alejandro, La independencia y la imparcialidad de la justicia arbitral, en Revista Chilena de Derecho 28 (2001) 3, pp. 509-535.

Vásquez Palma, María Fernanda, Tratado de arbitraje en Chile, Arbitraje interno e internacional ( $1^{\text {a }}$ edición, Santiago, Thomson Reuters, 2018).

${ }^{13}$ Por supuesto, el libro de AylWIn, cit. (n. 10), es un referente obligado, pero no puede olvidarse que este texto data de 1948, y desde esta fecha la institución ha evolucionado notablemente. Estar al día en estos conocimientos es una obligación de todo operador jurídico, principalmente de los sentenciadores. 